\title{
Seasonal variation in starvation resistance of early larval North Sea shrimp Crangon crangon (Decapoda: Crangonidae)
}

\author{
Kurt A. Paschke ${ }^{1}$, P. Gebauer ${ }^{1}$, F. Buchholz ${ }^{2}$, K. Anger ${ }^{2, *}$ \\ ${ }^{1}$ Facultad de Pesquerías y Oceanografía, Universidad Austral de Chile, Casilla 1327, Puerto Montt, Chile \\ ${ }^{2}$ Biologische Anstalt Helgoland, Stiftung Alfred-Wegener-Institut für Polar- und Meeresforschung, 27498 Helgoland, Germany
}

\begin{abstract}
The North Sea shrimp Crangon crangon (Linnaeus, 1758) has seasonal dimorphism in egg size, with larger winter eggs and smaller summer eggs. In the laboratory, we compared the tolerance of nutritional stress in Zoea I larvae hatching from the different types of eggs (referred to as 'winter larvae', WL, and 'summer larvae', SL, respectively). Starvation tolerance was quantified as median point-of-no-return $\left(\mathrm{PNR}_{50}\right)$ and point-of-reserve-saturation $\left(\mathrm{PRS}_{50}\right) . \mathrm{PNR}_{50}$ is defined as the time when $50 \%$ of starved larvae have lost the capability to recover (after subsequent feeding); $\mathrm{PRS}_{50}$ is the time when $50 \%$ of fed larvae attain the capability to develop through the rest of the moulting cycle using internally stored energy reserves. These critical points in the moulting cycle were estimated by fitting sigmoidal dose-response curves of cumulative mortality to the time of initial starvation or feeding, respectively. Significant seasonal variation was observed in the initial biomass at hatching (16.2 vs $14.7 \mathrm{\mu g}$ dry mass in WL and SL, respectively) as well as in the development duration of continuously fed larvae (fed controls, FC; average Zoea I stage durations: 4.4 vs $5.0 \mathrm{~d}$ ). Likewise, WL showed a consistently shorter development duration after 1 to $4 \mathrm{~d}$ initial starvation and subsequent feeding (PNR treatments). In treatments with 3 to $5 \mathrm{~d}$ initial starvation, mortality was also significantly lower in WL than in SL. Both larval groups showed an increasingly delayed moult to the Zoea II stage with increasing time of initial starvation, but this effect was significantly weaker in WL than in SL. As a consequence, the mean PNR 50 value was higher in WL than in SL (4.8 vs 3.5). When zoeae were continuously starved from hatching onwards (starved controls, SC), WL were able to survive significantly longer than SL (8.8 vs 6.4 d). In experiments with differential periods of initial feeding and subsequent starvation (PRS experiments), $50 \%$ of the WL exceeded their PRS after only $1 \mathrm{~d}$ of food availability, while SL required at least $2 \mathrm{~d}$ of feeding to become independent of further food supply. PSR ${ }_{50}$ values of WL and SL differed significantly (1.0 vs $1.6 \mathrm{~d}$ ). Our results indicate a shorter development and stronger starvation resistance in WL compared to SL. Seasonal variation in egg size and initial biomass and physiological condition of early larvae allow for an extended period of reproduction, including larval hatching under conditions of low or unpredictable planktonic food availability in winter and early spring.
\end{abstract}

KEY WORDS: Crangon crangon - Egg size $\cdot$ Point-of-no-return $\cdot$ PNR $\cdot$ Point-of-reserve-saturation · PRS $\cdot$ Seasonal variation $\cdot$ Starvation resistance $\cdot$ Nutritional vulnerability $\cdot$ Zoea

\section{INTRODUCTION}

Fluctuations in population density have been documented for numerous benthic marine invertebrates, including crustaceans (reviews by Caddy 1989, Eckert 2003). In species with planktotrophic larvae, this variability has mainly been attributed to fluctuation in brood size and to variation in growth and mortality during the larval and early juvenile phases of the life cycle (Modlin 1980, Morgan 1995, Moksnes \& Wennhage 2001).

Food is considered one of the key factors controlling the survival of planktotrophic meroplanktonic larvae in general (Boidron-Métairon 1995). In temporally and 
spatially patchy environments such as the marine plankton, temporal lack of suitable food sources is likely to occur both regionally and seasonally. In decapod crustacean larvae, this variability in nutritional conditions may affect various physiological and behavioural features, enhancing the rate of mortality and the duration of development in the pelagic environment (for reviews, see D'Abramo et al. 1997, Anger 2001).

The dietary requirements of the first larval stage may vary inter- and intraspecifically as well as seasonally or interannually, depending on energy reserves and essential nutrients stored in the egg yolk, and on larval abilities to synthesize macromolecular nutrients from precursors (Staton \& Sulkin 1991, Kattner et al. 1994, Paschke 1998). As a consequence of a rapid depletion of yolk reserves, the larvae of most marine invertebrate and fish species must start feeding within a limited time after hatching to avoid starvation effects. Based on observations in larval herring, Blaxter \& Hempel (1963) coined the term 'point-of-no-return' (PNR). This critical point within larval development represents a threshold where starved and subsequently fed larvae, which still may remain alive for an extended period, cannot recover from previous nutritional stress, and lose their capability to develop further.

Anger \& Dawirs (1981) first demonstrated the existence of a PNR in decapod crustacean larvae. Moreover, they discovered a 'point-of-reserve-saturation' (PRS), beyond which food uptake is no longer essential for subsequent development and moulting to the following larval stage; this critical point was later found to be identical with the transition between Stages C (intermoult) and $\mathrm{D}_{0}$ (early premoult) of the moulting cycle, and thus, was renamed ' $\mathrm{D}_{0}$ threshold' (Anger 1987).

As pointed out by Yin \& Blaxter (1987), information on the PNR in relation to spawning time and concentration of suitable food in the sea may help to predict the survival of different broods and to understand the factors controlling recruitment in the natural environment. Moreover, knowledge of critical points in initial feeding may aid in maximising larval survival and metamorphosis in both research cultivation (see Kinne 1977) and aquaculture of commercially exploited species. In crustacean larvae, both the PNR and the PRS can be quantified experimentally to characterise the 'nutritional vulnerability' (Sulkin 1978) or 'nutritional flexibility' (Sulkin \& van Heukelem 1980). Since these measurements of larval starvation resistance should vary with the general level of larval fitness (e.g. due to genetic differences, maternal factors, previous or concomitant exposure to physico-chemical or other stress, etc.), they may also be useful as condition indices (Anger 2001).

The North Sea shrimp Crangon crangon (Linnaeus, 1758) (Decapoda: Crangonidae) is considered one of the key species in the ecology of the North Sea. It is intensively exploited by coastal fisheries, and plays an important role both as a prey for demersal fishes and as a predator of benthic and planktonic organisms (see e.g. Plagmann 1939, Tiews 1970, Kuipers \& Dapper 1984, Gibson et al. 1995, Spaargaren 2000). Its reproductive cycle in the southern North Sea is characterised by seasonal variation in egg size, with smaller 'summer eggs' and larger 'winter eggs' (Havinga 1930, Boddeke 1982); correspondingly, larval size has also been observed to vary seasonally (Criales 1985, Linck 1995, Paschke 1998). These differences have commonly been ignored in stock management and modelling, mainly due to lack of information on the chemical composition and energy content of eggs, embryonic and larval development times, and nutritional needs of the early larval stages.

Paschke (1998) observed that winter eggs have significantly higher dry mass and carbon content than summer eggs, indicating that seasonal variation in the size of eggs and larvae is associated with variation in reserve allocation during egg production. Thus, differences in the initial energy content of newly hatched larvae may result in various degrees of larval dependence on food availability (see Giménez 2002, Giménez et al. 2004). Herein, we conducted PNR and PRS experiments to assess whether Crangon crangon larvae originating from winter or summer eggs differ in nutritional vulnerability.

\section{MATERIALS AND METHODS}

Sexually mature Crangon crangon were dredged in winter (March) and summer (August) from the Elbe estuary (southeastern North Sea; $54^{\circ} 03^{\prime}$ to $54^{\circ} 04^{\prime} \mathrm{N}$; $8^{\circ} 18^{\prime}$ to $8^{\circ} 24^{\prime} \mathrm{E}$ ) from $712 \mathrm{~m}$ depth and transported to the Helgoland Marine Biological Station. The ambient near-bottom conditions of temperature and salinity at the site and time of sampling were $18.5^{\circ} \mathrm{C}, 29.5 \%$ in summer and $2.8^{\circ} \mathrm{C}, 29.4 \%$ in winter. In the laboratory, groups of 2 female and 3 male shrimps were placed in flow-through seawater aquaria with similar conditions of temperature and salinity. In all females tested in our experiments, moulting and egg laying occurred successively within 5 d. Subsequently, ovigerous females were transferred individually to flow-through seawater aquaria (ca. $32 \%$, constant $15^{\circ} \mathrm{C}$ ) with sand as a substrate; fresh mussel meat was added every other day as food until larvae hatched.

In both seasons, freshly hatched larvae from each of 2 females were isolated and reared individually in $100 \mathrm{ml}$ beakers with ca. $80 \mathrm{ml}$ filtered seawater (ca. $1 \mu \mathrm{m}$ pore size) with constant temperature $\left(15^{\circ} \mathrm{C}\right)$, salinity $(32 \%)$, and a 12:12 h L:D photoperiod. The 
total length of the 2 summer females whose larvae were used in our experiments was 52 and $57 \mathrm{~mm}$, that of the 2 winter females was 50 and $52 \mathrm{~mm}$.

The PNR experiments comprised 8 treatments with 1 to $8 \mathrm{~d}$ initial starvation (beginning at hatching) followed by continuous feeding (Treatments S1-S8; Fig. 1; for more details, cf. Anger \& Dawirs 1981, Anger 1987, Staton \& Sulkin 1991). In the PRS experiments, the larvae were fed from hatching for 1 to $6 \mathrm{~d}$, followed by continuous starvation (Treatments F1-F6; Fig. 1). We used 2 groups of larvae, which were continually fed or starved as a positive and a negative control group (FC, SC), respectively, for both the PNR and PRS experiments.

From these data, median values $\left(\mathrm{PNR}_{50}, \mathrm{PRS}_{50}\right)$ could be estimated. $\mathrm{PNR}_{50}$ is defined as the time when $50 \%$ of initially starved larvae have lost the capability to recover from previous starvation, and therefore cannot develop further after later feeding. $\mathrm{PRS}_{50}$ is the time when $50 \%$ of initially fed larvae attain the capability to develop through the rest of the moulting cycle using previously accumulated internal energy stores, independently of subsequent availability of food.

Each experimental treatment and each control group initially comprised 24 larvae from the same female; since larvae from 2 different females were used per season (winter, summer) and per experiment, the material in this study comprised 8 PNR treatments $(\mathrm{S} 1-8) \times 24$ larvae $\times 2$ females $\times 2$ seasons $=768$ larvae, 6 PRS treatments $(\mathrm{F} 1-6) \times 24$ larvae $\times 2$ females $\times 2$ seasons $=576$ larvae, and 2 controls $(F C, S C) \times 24$ larvae $\times 2$ females $\times 2$ seasons $=192$ larvae; i.e. a total of 1536 individually reared larvae. Statistical comparisons of larval mortality rates and development duration in identical treatments and seasons revealed no significant differences between the 2 females (or larval hatches) used. Hence, these data were later pooled, resulting in $\mathrm{n}=48$ larvae per treatment or control for each experiment and each season.

The experiments were checked daily for larval survival and moulting, and the water was changed and food was given (freshly hatched Artemia sp. nauplii where applicable, cf. Fig. 1). Larvae were considered dead when no peristaltic intestinal (or any other) movements were observed under a Wild stereo microscope within 30 s. Preliminary tests had shown that no larvae were alive $1 \mathrm{~d}$ after intestinal contractions had ceased. For moulting, culture bowls were checked daily for the presence of exuviae, and the larvae were examined microscopically for characteristic morphological changes (sessile vs stalked eyes, changing telson morphology; see Gurney 1982). When larvae were transferred from a feeding to a starvation condition (Fig. 1), they were first washed in filtered seawater to avoid accidental transfer of food organisms. The experiments were terminated when all larvae had either moulted to the Zoea II stage or had died.

Statistical analysis of survival and development data followed standards methods (Sokal \& Rohlf 1995). Normal distribution and homogeneity of variances were tested with Kolmogorov-Smirnov and Levene median tests, respectively. When the data did not satisfy the prerequisites for parametric tests of differences among mean development durations in the various treatments of an experiment (analysis of variance, ANOVA), Kruskal-Wallis $H$-tests were used. An overall comparison of the developmental response of winter and summer larvae to initial starvation periods (PNR experiments) was carried out as a comparison of the slopes of 2 linear regressions (developmental delay plotted against time of starvation), using a test of equality of slopes (Sokal \& Rohlf 1995, p. 493). Pairwise comparisons of development duration in winter and summer larvae (same treatments) were made by a Student's $t$ test (parametric) or a Mann-Whitney $U$-test (non-parametric).

Mortality data were analysed using contingency tables (G-test for homogeneity). Subsequently, unplanned comparisons were carried out to test whether all treatments differed from each other (Sokal \& Rohlf 1995). Assuming that a given time of starvation is comparable with the effects exerted by a given dose of a



Fig. 1. Crangon crangon. Experimental design of point-of-no-return (PNR initial starvation, followed by feeding) and point-of-reserve-saturation (PRS initial feeding, followed by starvation) experiments. FC: continuously fed control; SC: continuously starved control; S1-S8: no. of days starved, followed by continuous feeding; F1-F6: no. of days fed, followed by continuous starvation. Initial number of larvae per treatment, $\mathrm{n}=48$; same FC and SC groups ( $\mathrm{n}=48$ each) were used for both PNR and PRS experiments 


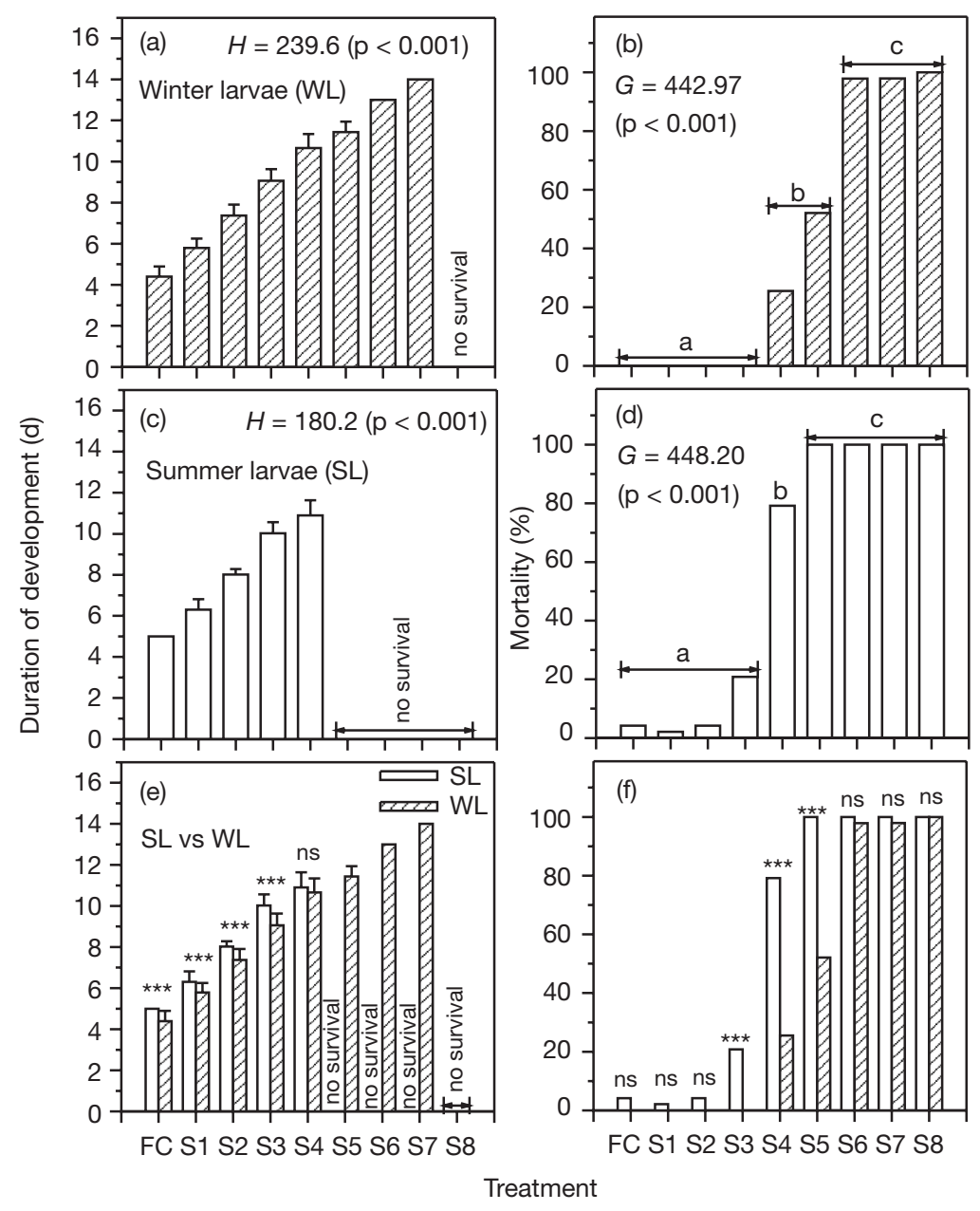

Fig. 2. Crangon crangon. PNR experiments. (a, c, e) Duration of Zoea I development; (b, d, f) mortality (\%). (a-d) Statistical comparisons for WL and SL; among different treatments (e-f) Statistical comparisons between WL and SL in identical treatments. $H$ : Kruskal-Wallis statistic; $G$ : statistic of unplanned tests for homogeneity; ${ }^{* * *}$ highly significant difference $(\mathrm{p}<0.0001)$, MannWhitney $U$-test; ns: not significant ( $p>0.05)$; for further details see Fig. 1 and 'Materials and methods'

toxic substance, the determination of $\mathrm{PNR}_{50}$ values for winter and summer larvae followed the same procedures used to estimate the lethal dose for $50 \%$ of test animals in toxicity tests, i.e. the $\mathrm{LD}_{50}$ value. When the probability of error for rejecting the null hypothesis was higher than 0.05, differences were considered not significant (ns).

\section{RESULTS}

\section{Control groups}

Continuously fed control (FC) winter larvae (WL) and summer larvae (SL) moulted on average after $4.4 \pm$ 0.5 and $5.0 \pm 0.0 \mathrm{~d}$, respectively, to the Zoea II stage.
This difference in the Stage I development duration of well-fed WL and SL reared under identical conditions was statistically highly significant (Mann-Whitney $U$-test, $\mathrm{p}<0.0001$; Fig. 2e). In both FC groups, the survival rate was very high (100 and 96\%, respectively; difference ns). Continuous lack of food (negative control or starved control, SC), on the other hand, did not allow any successful development to the Zoea II stage. The WL died, on average, after $8.8 \pm 1.4 \mathrm{~d}$, the SL after $6.4 \pm 0.8 \mathrm{~d}$ starvation (maxima: 13 vs $10 \mathrm{~d}$; MannWhitney $U$-test, $\mathrm{p}<0.0001$ ).

\section{PNR experiments}

With increasing time of initial starvation, a decreasing percentage of both WL and SL survived to the second zoeal stage, with a significantly increasing developmental delay (Fig. 2). While some WL were capable of recovering (after subsequent feeding) from up to $7 \mathrm{~d}$ of preceding starvation (Treatment S7), SL tolerated a maximum of $4 \mathrm{~d}$ initial lack of food. In treatments with 1 to $3 \mathrm{~d}$ starvation (S1 to S3), the development duration for Zoea I was significantly shorter in WL than in SL (Mann-Whitney $U$-test, $\mathrm{p}<0.0001$; Fig. 2e); this difference was visible also in the S4 treatment, but here it was weaker and statistically not significant, mainly due to low numbers of survivors.

In both seasonal groups, the delay in the duration of the first larval stage could be described as a linear function of the time of initial starvation. Analysis of equality of slopes showed that these regression lines differed significantly in their slope $(\mathrm{p}<0.0001$; Table 1$)$, indicating a weaker delaying effect of initial starvation on the development of WL compared to that of SL.

Comparison of mortality patterns between WL and SL showed that the former again had a weaker overall response to PNR treatments. While short initial starvation periods of up to $2 \mathrm{~d}$ did not play a differential role in these seasonal groups, longer starvation (Treatments S3-S5; Fig. 2f) caused significantly lower mortality in WL than in SL (G-tests, p < 0.0001). As a consequence, the $\mathrm{PNR}_{50}$ value was significantly higher in WL (see Fig. $4 \mathrm{a}$; $t$-test, $\mathrm{p}<0.0001$ ), indicating a later occurrence of irreversible nutritional stress effects in WL than in SL. After very long starvation periods (Treatments S6-S8), no (SL) or only very few individu- 
Table 1. Crangon crangon. (a) Linear regressions between duration of initial starvation (in days, point-of-no-return experiment) and developmental delay (d) for winter and summer larvae, showing coefficient of determination $\left(\mathrm{r}^{2}\right)$ and probability level for null hypothesis (slope $=0$ ); (b) test for equality of slopes of regression lines for WL and SL. Slopes in (a) differ significantly

\begin{tabular}{|lrccc|}
\hline (a) & Intercept & Slope & $\mathrm{r}^{2}$ & $\mathrm{p}<$ \\
\hline Winter larvae (WL) & 0.018 & 1.490 & 0.993 & 0.0001 \\
Summer larvae (SL) & -0.123 & 1.616 & 0.989 & 0.0001 \\
(b) & & & & \\
Source of variation & df & Mean square & $F$-ratio & $\mathrm{p}<$ \\
\hline Time of initial starvation (d) & 1 & 1869.898 & 44717.304 & 0.0001 \\
Season (WL; SL) & 1 & 0.777 & 18.583 & 0.0001 \\
Among regressions & 1 & 3.068 & 73.360 & 0.0001 \\
Weighted average of deviations & 433 & 0.042 & & \\
from regression (average & & & & \\
variation within regressions) & & & & \\
\hline
\end{tabular}

time among Treatments F2-F6 (Fig. $3 \mathrm{c})$. When development duration in identical treatments (F2-F6) is compared between WL and SL, consistently shorter Zoea I durations are apparent for WL (Mann-Whitney $U$ test, all $\mathrm{p}<0.0001$; Fig. 3e).

As in the PNR experiments, the mortality patterns of WL also revealed a generally weaker response to variation in feeding conditions than SL. These differences were clearest in Treatments F1-F2, where significantly lower mortality occurred in WL (Gtests, $\mathrm{p}<0.0001$ and $<0.05$; Fig. 3f); this is reflected also in significantly als (WL) were able to survive to the Zoea II stage, so that differences in mortality were statistically not significant between these treatments and the continuously starved control groups (SC, with complete mortality), nor between WL and SL (Fig. 2f).

\section{PRS experiments}

While no successful development to the second Zoeal stage occurred in the continually starved control (SC) group of either WL or SL, a single day of initial feeding (F1 treatment) sufficed for $50 \%$ of the WL to survive through the first larval moult during a subsequent absence of food (Fig. 3f). In contrast, SL, showed complete mortality after $1 \mathrm{~d}$ of feeding and subsequent starvation, i.e. during a single day of food availability SL were not able to accumulate sufficient energy reserves to complete (independent of later food availability) the remainder of the Zoea I moulting cycle. However, the average time of survival was significantly enhanced in the $\mathrm{F} 1$ treatment compared to the SC group (8.0 \pm 1.0 vs $6.4 \pm 0.8 \mathrm{~d}$; Mann-Whitney $U$-test, $\mathrm{p}<0.0001)$.

In WL, mean development duration was slightly shorter (statistically significant) in F3 and F5 than in all other treatments (Fig. 3a) including FC (cf. Fig. 2a). This cannot be explained by differential feeding and starvation. Similarly, SL showed no significant differences in development


Fig. 3. Crangon crangon. PRS experiments. $(\mathrm{a}, \mathrm{c}, \mathrm{e})$ Duration of Zoea I development; (b, d, f) mortality $(\%) .{ }^{*}$ Significant difference $(p<0.05)$, Mann-Whitney $U$-test; further details as in legend to Fig. 2 
different $\mathrm{PRS}_{50}$ values, calculated as $1.0 \pm 0.2$ versus $1.6 \pm 0.5 \mathrm{~d}$ for WL and SL, respectively (Fig. $4 \mathrm{~b}$; $t$-test, $\mathrm{p}<0.01)$. Comparing these values with the corresponding development durations of the continuously fed control (FC) groups, one can thus say that $50 \%$ of the WL became independent of further food supply during the Zoea I stage, when they had been fed during the initial $23 \%$ of moulting cycle. By comparison, SL required an initial ad libitum feeding time corresponding to $32 \%$ of the moult-cycle duration to reach their 'reserve saturation' point allowing subsequent food-independent development to the second larval stage.

\section{DISCUSSION}

The North Sea shrimp Crangon crangon, a commercially exploited and ecologically important decapod crustacean, is known to produce eggs and early larvae of seasonally variable size (Havinga 1930, Boddeke 1982, Criales 1985, Linck 1995). This reproductive pattern appears to be ubiquitous, resembling trends in intraspecific latitudinal variation in the size and dry mass of eggs that have been observed, for instance, in crab and shrimp species with a wide range of geographic-climatic distribution along the Chilean coast, with an increase in egg size from warmer towards colder regions (Lardies \& Castilla 2001, Lardies \& Wehrtmann 2001).

Due to variability in the concentration of energy and organic matter in caridean shrimp eggs (Anger et al. 2002), variation in size or volume does not necessarily correspond to a similar variation in biomass measured as dry mass, carbon, or nitrogen content. In Crangon crangon, however, a positive correlation between egg size and biomass was observed, with eggs produced in winter tending to be larger and richer in organic matter than summer eggs (Paschke 1998). In the present study, we tested if larvae hatching from winter eggs (referred to as as winter larvae, WL) are more resistant to temporary lack of food or less dependent on initial feeding than summer larvae (SL).

Under identical rearing conditions, WL had a generally shorter development time through the Zoea I moulting cycle than SL. This suggests an inverse relationship between the quantity of internally stored energy reserves and early larval development duration in Crangon crangon. Such relationships have frequently been described for interspecific comparisons (for reviews see McConaugha 1985, Anger 2001), while few data are available for the assessment of intraspecific variability in reproductive energy investment in egg production and implications for variability in developmental rates.

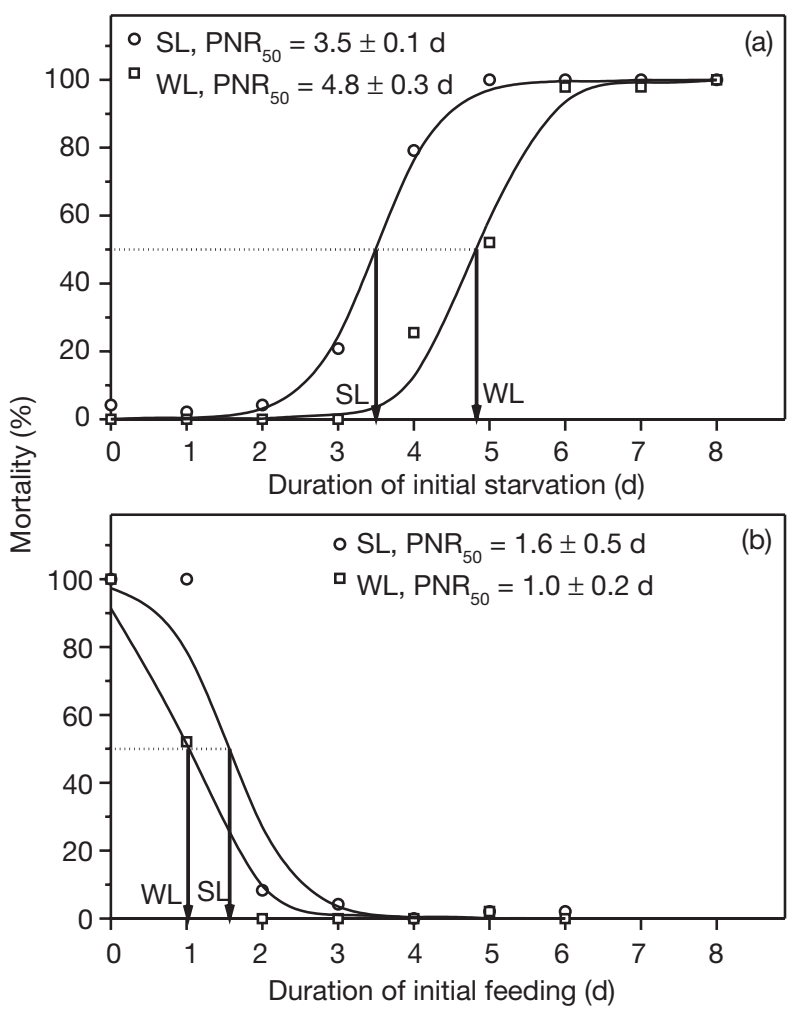

Fig. 4. Crangon crangon. Cumulative mortality $(\% ; n=48)$ in Zoea I stage in relation to (a) time of initial starvation (PNR experiments) and (b) time of initial feeding (PRS experiments). WL: winter larvae; SL: summer larvae; $\mathrm{PNR}_{50}$ : average point-of-no-return (time when $50 \%$ of initially starved larvae have lost capability to recover after subsequent feeding); $\mathrm{PRS}_{50}$ : average point-of-reserve-saturation (time when $50 \%$ of initially fed larvae have accumulated sufficient energy reserves to enable subsequent food-independent development); $\mathrm{PNR}_{50}$ and $\mathrm{PRS}_{50}$ values (means $\pm \mathrm{SD}$ ) estimated from non-linear dose-response fitting (see 'Materials and methods')

Our data suggest that an inverse relationship between egg size and the rate of development may occur also within a single species. The availability of higher internal energy reserves in WL (Paschke 1998) appears to allow for a reduced time of planktonic feeding (i.e. less accumulation of externally gathered energy) and an accelerated development through the first moulting cycle. This developmental acceleration should be particularly important under the cold conditions predominating throughout late winter and early spring when WL hatch, and may partially compensate for the delaying effect of low temperatures. Short larval development may reduce the time of exposure to predation and other potential risks in the plankton, and thus may enhance the chance of successful recruitment (Pechenik 1979, Morgan 1995). It remains an open question, however, if the initial advantage of a seasonally enhanced reproductive energy allocation 
per offspring is fully retained throughout later larval stages. As pointed out by McConaugha (1985), a delay or acceleration in one stage does not necessary imply a change in complete development duration, as there may be compensatory growth mechanisms at later stages. On the other hand, stress-induced delay in the development of earlier stages may also persist, even through metamorphosis, and cause a reduced fitness in later larval or juvenile stages (Wehrtmann 1991, Pechenik et al. 1998, Gebauer et al. 1999, Pechenik 1999, Giménez 2003, Giménez et al. 2004). Late effects of early starvation may thus also occur in advanced stages (see e.g. Anger 1987, Wehrtmann 1991), but these have been little studied. In the case of the WL of Crangon crangon, enhanced nutritional flexibility of the initial stages may be a sufficient adaptation to hatching under winter conditions, as later stages will develop and grow under gradually improving conditions, with an increase in both water temperature and food availabilty during the spring season.

Crangon crangon zoeae (both WL and SL) showed a linear relationship between moult-cycle duration and the duration of initial starvation periods, as has been documented for numerous other species of larval crabs, shrimps, and lobsters (for references see Anger 2001). WL exposed to conditions of initial lack of food (PNR treatments) generally showed a stronger resistance (lower mortality) and a weaker functional response (smaller delay of Zoea I development duration) than SL. A significantly higher $\mathrm{PNR}_{50}$ value in $\mathrm{WL}$ indicates that these larvae are capable of tolerating longer periods of initial starvation without suffering irreversible damage. After about $5 \mathrm{~d}$ initial starvation, practically all SL had already reached their PNR, but only $50 \%$ of the WL had done so (see Fig. 4a). Consistent with these observations, under conditions of continual lack of food, WL were also nutritionally less vulnerable, surviving with their internal energy reserves for a significantly longer time than SL.

In experiments with temporally limited initial food availability (PRS treatments), shorter periods of feeding were necessary for WL than for SL (about 23 vs $32 \%$, respectively, of the average stage duration in the fed controls). In other words, SL required longer periods of food uptake to accumulate sufficient dietary energy reserves for further food-independent development through the rest of the moulting cycle. Previous comparative studies of the PRS have shown that this critical point is generally passed when a larva has reached the early premoult stage of the moulting cycle (Stage $\mathrm{D}_{0}$; see Anger 1987, 2001). This implies that, under conditions of unlimited food availability, WL would reach this critical stage earlier than identically treated SL. This inference, however, remains to be checked microscopically in future research.
$\mathrm{PNR}_{50}$ and $\mathrm{PRS}_{50}$ values (especially those obtained with a non-linear dose-response fitting method, which allows estimates of variability and other statistical comparisons, as opposed to those estimated graphically) certainly constitute more reliable measures of larval starvation resistance or dependence on food than does the maximum time of survival during a complete absence of food. The latter method may substantially overestimate the average tolerance of nutritional stress, because irreversible damage occurs long before the death of a larva; moreover, mortality curves reveal a high level of individual variability among identically treated sibling larvae (see Fig. 4). Since the nutritional vulnerability of a larva should reflect its general physiological condition or health, $\mathrm{PNR}_{50}$ and $\mathrm{PRS}_{50}$ values can also be used as functional condition indices, which may complement or sometimes even replace biochemical indices of larval fitness.

In summary, the present data provide experimental evidence of seasonal variation in larval dependence on food, or in susceptibility to transitory starvation, coinciding with seasonal differences in the size and biomass of the eggs and larvae. Variable amounts of energy-rich organic substances are produced during oogenesis and stored in the egg yolk. These are partially utilised during embryogenesis, with varying amounts remaining available as an energy reserve for early planktonic larvae, and larger reserves remaining at hatching in the WL (Paschke 1998). Hence, Crangon crangon produces nutritionally less vulnerable (or nutritionally more flexible; for concepts, see Sulkin 1978, Sulkin \& van Heukelem 1980, Staton \& Sulkin 1991) larvae in winter and early spring, when plankton production is on average low or unpredictable. As a consequence, successful larval development may also occur under poor nutritional conditions. On the other hand, the same species may produce a higher number of smaller eggs in summer, allowing for an efficient resource exploitation when sufficient planktonic food is available. Since this reproductive and bioenergetic flexibility is advantageous in temperate waters, where strong but regular (i.e. predictable) seasonal fluctuations in plankton production occur (see e.g. Fransz et al. 1991a,b, Broekhuizen \& McKenzie 1995), this trait should have an adaptive value. This opportunistic strategy allows $C$. crangon to extend its reproductive period, which in most other species is restricted to late spring and early summer. In addition, temperaturerelated intraspecific variation in size and biomass of eggs may enable a wide geographic distribution over various climatic regions (see Lardies \& Castilla 2001, Lardies \& Wehrtmann 2001), and this may also apply to C. crangon, which is distributed from the cold-temperate North Atlantic and Baltic Sea to the subtropical Mediterranean (Tiews 1970). Future research should 
thus also compare reproductive and larval traits among populations of this species in different climatic regions.

Acknowledgements. This study was supported by the Deutscher Akademischer Austauschdienst (DAAD) and Biologische Anstalt Helgoland (BAH; grants DID F-98-06 and DID S200159 to K.A.P, grant DID D2001-12 to P.G.).

\section{LITERATURE CITED}

Anger K (1987) The $\mathrm{D}_{0}$ threshold: a critical point in the larval development of decapod crustaceans. J Exp Mar Biol Ecol 108:15-30

Anger K (2001) The biology of decapod crustacean larvae. In: Crustacean issues, Vol 14. AA Balkema, Lisse

Anger K, Dawirs R (1981) Influence of starvation on the larval development of Hyas araneus (Decapoda, Majidae). Helgol Wiss Meeresunters 34:287-311

Anger K, Moreira GS, Ismael D (2002) Comparative size, biomass, elemental composition $(\mathrm{C}, \mathrm{N}, \mathrm{H})$, and energy concentration of caridean shrimp eggs. Invertebr Reprod Dev 42:83-93

Blaxter JH, Hempel G (1963) The influence of egg size on herring larvae (Clupea harengus L.). J Cons Perm Int Explor Mer 28:211-240

Boddeke R (1982) The occurrence of winter and summer eggs in the brown shrimp (Crangon crangon) and the pattern of recruitment. Neth J Sea Res 16:151-162

Boidron-Métairon IF (1995) Larval nutrition. In: McEdward LR (ed) Ecology of marine invertebrate larvae. CRC Press, Boca Raton, FL, p 223-248

Broekhuizen N, McKenzie E (1995) Patterns of abundance for Calanus and smaller copepods in the North Sea: time series decomposition of two CPR data sets. Mar Ecol Prog Ser 118:103-120

Caddy J (1989) Marine invertebrate fisheries: their assessment and management. J Wiley \& Sons, New York

Criales MM (1985) Untersuchungen zur Larvalentwicklung von Crangon crangon L. und Crangon allmanni Kinahan (Decapoda, Natantia, Caridea). PhD thesis, Universität Kiel

D'Abramo LR, Conklin DE, Akiyama DM (1997) Crustacean nutrition. Advances in World Aquaculture 6. World Aquaculture Society, Louisiana State University, Baton Rouge, LA

Eckert GL (2003) Effects of the planktonic period on marine population fluctuations. Ecology 84:372-383

Fransz HG, Colebrook JM, Gamble JC, Krause M (1991a) The zooplankton of the North Sea. Neth J Sea Res 28:1-52

Fransz HG, Mommaerts JP, Radach G (1991b) Ecological modelling of the North Sea. Neth J Sea Res 28:67-140

Gebauer P, Paschke K, Anger K (1999) Costs of delayed metamorphosis: reduced growth and survival in early juveniles of an estuarine grapsid crab, Chasmagnathus granulata. J Exp Mar Biol Ecol 238:271-281

Gibson RN, Yin MC, Robb L (1995) The behavioural basis of predator-prey size relationship between shrimp (Crangon crangon) and juvenile plaice (Pleuronectes platessa). J Mar Biol Assoc UK 75:337-349

Giménez L (2002) Effects of prehatching salinity and initial larval biomass on survival and duration of development in the Zoea 1 of the estuarine crab, Chasmagnathus granulata, under nutritional stress. J Exp Mar Biol Ecol 270: 93-110
Giménez L (2003) Potential effects of physiological plastic responses to salinity on population networks of the estuarine crab Chasmagnathus granulata. Helgol Mar Res 56: 265-273

Giménez L, Torres G, Anger K (2004) Linking life history traits in successive phases of a complex life cyle: effects of larval biomass on early juvenile development in an estuarine crab, Chasmagnathus granulata. Oikos 104:570-580

Gurney (1982) The larval development of Crangon crangon (Fabr, 1795) (Crustacea: Decapoda). Bull Br Mus (Nat Hist) Zool 42:247-262

Havinga B (1930) Der Granat (Crangon vulgaris Fabr.) in den holländischen Gewässern. J Cons Perm Int Explor 5:57-87

Kattner G, Wehrtmann IS, Merck T (1994) Interannual variations of lipids and fatty acids during larval development of Crangon spp in the German bight, North Sea. Comp Biochem Physiol 107B(1):103-110

Kinne O (1977) Research cultivation. In: Kinne O (ed) Marine ecology, Vol 3. Wiley, Chichester, p 579-1293

Kuipers B, Dapper R (1984) Nursery function of Wadden Sea tidal flats for the brown shrimp Crangon crangon. Mar Ecol Prog Ser 17:171-181

Lardies MA, Castilla JC (2001) Latitudinal variation in the reproductive biology of the commensal crab Pinnaxodes chilensis (Decapoda: Pinnotheridae) along the Chilean coast. Mar Biol 139:1125-1133

Lardies MA, Wehrtmann IS (2001) Latitudinal variation in the reproductive biology of Betaeus truncatus (Decapoda: Alpheidae) along the Chilean coast. Ophelia 55:55-67

Linck BM (1995) Einfluß von Temperatur und Salzgehalt auf die Larven der Nordseegarnele Crangon crangon. MS thesis, Universität Oldenburg

McConaugha J R (1985) Nutrition and larval growth. In: Wenner A (ed) Crustacean growth: larval growth. AA Balkema, Rotterdam, p 127-154

Modlin R (1980) The life cycle and recruitment of the sand shrimp, Crangon septemspinosa, in the Mystic River Estuary, Connecticut. Estuaries 3:1-10

Moksnes PO, Wennhage H (2001) Methods for estimating decapod larval supply and settlement: importance of larval behavior and development stage. Mar Ecol Prog Ser 209:257-273

Morgan SG (1995) Life and death in the plankton: larval mortality and adaptation. In: McEdward LR (ed) Ecolology of marine invertebrate larvae. CRC Press, Boca Raton, FL, p 279-321

Paschke K (1998) Untersuchungen zum Energiestoffwechsel während der Embryonalentwicklung der NordseeGarnele Crangon crangon (Linnaeus 1758) (Decapoda: Caridea). PhD thesis, Universität Hamburg

Pechenik J (1979) Role of encapsulation in invertebrate life histories. Am Nat 114:859-870

Pechenik J (1999) On the advantages and disadvantages of larval stages in benthic marine invertebrate life cycles. Mar Ecol Prog Ser 177:269-297

Pechenik J, Wendt D, Jarret J (1998) Metamorphosis is not a new beginnig. BioScience 48:901-910

Plagmann J (1939) Ernährungsbiologie der Garnele (Crangon vulgaris Fabr.). Helgol Wiss Meeresunters 2:113-162

Sokal R, Rohlf F (1995) Biometry: the principles and practice of statistics in biological research; 3rd edn. WH Freeman, New York

Spaargaren D (2000) Seasonal and annual variations in the catches of Crangon crangon (L.,1758) (Decapoda, Natantia) near the coast of Texel, The Netherlands. Crustaceana 737:547-563

Staton J, Sulkin S (1991) Nutritional requirements and starva- 
tion resistance in larvae of the brachyuran crabs Sesarma cinereum (Bosc) and S. reticulatum (Say). J Exp Mar Biol Ecol 152:271-284

Sulkin SD (1978) Nutrional requirements during larval development of the portunid crab, Callinectes sapidus Rathbun. J Exp Mar Biol Ecol 34:29-41

Sulkin SD, van Heukelem WF (1980) Ecological and evolutionary significance of nutritional flexibility in planktotrophic larvae of the deep sea red crab Geryon quinquedens and the stone crab Menippe mercenaria. Mar Ecol

Editorial responsibility: Otto Kinne (Editor),

Oldendorf/Luhe, Germany
Prog Ser 2:91-95

Tiews K (1970) Synopsis of biological data on the common shrimp Crangon crangon (Linnaeus, 1758). FAO Fish Synop 91:1167-1224

Wehrtmann IS (1991) How important are starvation periods in early larval development for survival of Crangon septemspinosa larvae? Mar Ecol Prog Ser 73:183-190

Yin MC, Blaxter JS (1987) Feeding ability and survival during starvation of marine fish larvae reared in the laboratory. J Exp Mar Biol Ecol 105:73-83

Submitted: January 21, 2004; Accepted: June 1, 2004 Proofs received from author(s): September 6, 2004 